\title{
Ion-pairing liquid chromatographic method determination of ketoconazole and stress degradation in pharmaceutical formulations with fluorescence detection
}

\author{
Wisanu Thongchai ${ }^{\oplus}$ \\ ${ }^{1}$ Chemistry Program, Faculty of Science and Technology, Pibulsongkram Rajabhat University, Thailand
}

\begin{abstract}
Ion-pairing liquid chromatographic method was validated for determination of ketoconazole in shampoo and cream samples as per ICH guidelines. The chromatographic conditions were carried out in the isocratic mode using a mixture of methanol and $8 \mathrm{mM}$ sodium dodecyl sulfate $(\mathrm{pH} 5.5)$ in a ratio of $45: 55 \mathrm{v} / \mathrm{v} \%$, as mobile phase. The flow rate was set at $1.0 \mathrm{~mL} \mathrm{~min}^{-1}$. Chromolith RP-18e $(100 \times 4.6 \mathrm{~mm})$ was used as the analytical column with a fluorescence detection at an excitation wavelength of $260 \mathrm{~nm}$ and an emission wavelength of $375 \mathrm{~nm}$. The average percentage recovery of shampoo A, shampoo B, shampoo C, cream A and cream B were 99.88, 97.06, 99.58, 96.77 and 97.26, respectively. The limit of detection was $0.12 \mathrm{mg} \mathrm{L}^{-1}$. The drug decomposition under acid degradation, base degradation and oxidative degradation were found to be in the range of $91.63-94.70 \%$ indicating that the drug is resistant towards acidic conditions. The drug decomposition under thermal condition and photolysis condition were found to be in the range of $69.05-87.15 \%$ and $47.31-66.83 \%$ respectively, indicating that the drug decomposition is more sensitive under photolysis conditions. This method is suitable for the quality control of ketoconazole in commercial shampoo and creams.
\end{abstract}

Keywords: Ion-pairing liquid chromatography. Ketoconazole. Shampoo. Cream. Fluorescence detection.

\section{INTRODUCTION}

Ketoconazole (cis-1-acetyl-4-[4-[[2-(2,4dichlorophenyl)-2-(1H-imidazol-1-ylmethyl)-1,3dioxolan-4-yl]methoxy]phenyl]piperazine is an imidazole antifungal agent. As with other imidazole derivatives, it has five-membered ring structure containing two nitrogen atoms with the structure shown in Figure 1. Ketoconazole is available in many dosage forms; cream, shampoo, solution, gel and foam. The side effects of ketoconazole are itching, nausea, vomiting, abdominal pain, headache, dizziness, fatigue, impotence and blood count abnormalities. Rarely, ketoconazole has serious allergic reactions. Ketoconazole 1\% shampoo is used to treat dandruff and ketoconazole $2 \%$ shampoo is used to treat sun fungus. These shampoos may cause abnormal hair texture, scalp pustules, dry skin and itching. There may also be oiliness and dryness of the

\footnotetext{
*Correspondence: W. Thongchai. Chemistry Program, Faculty of Science and Technology, Pibulsongkram Rajabhat University, Phitsanulok 65000 - Thailand. E-mail: wisanuthongchai@hotmail.com
}

hair and scalp. Rarely, there may be some hair loss. Ketoconazole is the only member of the imidazole derivatives class that is currently used for treatment of systemic infections. Ketoconazole was more widely used before the development of newer, less toxic and more effective triazole compounds, fluconazole and itraconazole, its use has now been limited. It now appears as an alternative drug for specific indications. Ketoconazole works principally by inhibition of cytochrome P450 14 $\alpha$-demethylase. This enzyme is in the sterol biosynthesis pathway that leads from lanosterol to ergosterol (Lyman, Walsh, 1992). The affinity of ketoconazole for fungal cell membranes is less compared to that of fluconazole and itraconazole. Ketoconazole has thus more potential to affect mammalian cell membranes and induce toxicity (Como, Dismukes, 1994). An official method normally involves titration in non-aqueous solvent (The United States Pharmacopoeia, 2002; European Pharmacopoeia, 2002). Various analytical methods were reported for the determination of ketoconazole. They are spectrophotometric methods (Kedor-Hackmann, Nery, Santoro, 1994; Abdel-Gawad, 
1997; Sadeghi, Shamsipur, 1998; Khashaba et al., 2000; Farhadi, Maleki, 2002; Khalil, Ramin, 2002; Abou-Attia et al., 2003; Alizadeh, Rezakhani, 2012; Rane, Padmaja, 2012; Naveed, Jaweed, 2014), spectrofluorimetric methods (Khashaba et al., 2000), high performance liquid chromatography (Bernal et al., 2000; Bruijn et al., 2001; Bernal et al., 2002; Bajad et al., 2002; Vander Heyden et al., 2002; Nguyen et al., 2003; Abdel-Moety et al., 2003; Nguyen et al., 2004; Vertzoni, Reppas, Archontaki, 2006; Wang et al., 2016), stripping voltammetric and polarographic method (Arranz et al., 2003; El Ries et $a l ., 2013$ ) and capillary zone electrophoresis (Arranz et al., 2000; Velikinac et al., 2004), high performance thin layer chromatography (Suwanna, Boonsom, Saisunee, 2010). Ion-pairing liquid chromatographic (IPLC) method has also been utilized for the analysis of various sulphonamides (Rader, 1973; Su, Hartkopf, Karger, 1976). All of these ion-pairing methods used basic $\mathrm{pH}$ media, cationic counter-ion and various expensive organic solvents. The mechanism of ion-pair extraction and the separation of ionic compounds by reversed-phase liquid chromatography have also been documented (Higuchi, Michaelis, 1968; Bidlingmeyer, 1980). Recently, highly porous monolithic silica rod columns have been introduced, which have a bimodal pore structure with a large surface area (Leinweber et al., 2002; Tanaka et al., 2002; Smith, McNair, 2003). Due to this fact, higher flowrates can be applied while the column back-pressure is still low. These new columns not only enable flow-rates up to

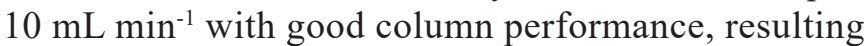
in very short run times, but also a very rapid column equilibration allowing a fast method change-over. This communication describes the development of the IPLC method using monolithic silica rod column technology and their applications to the quantitation of ketoconazole and degradation products in pharmaceutical products such as anti-dandruff shampoo and creams.

\section{MATERIAL AND METHODS}

\section{Chemicals and reagents}

Ketoconazole (Reference standard assay $\geq 98 \%$, Sigma, Switzerland) was used for reference standard. Acetonitrile and methanol (CHROMASOLVTM ${ }^{\mathrm{T}}$, gradient grade, for HPLC, $\geq 99.9 \%$ ) were purchase from Merck KGaA (Darmstadt, Germany). Sodium dodecyl sulfate (SDS), cetylmethylammonium bromide (CTAB), polyoxyethylene lauryl ether (Brij $\left.{ }^{\circledR} 35\right)$, sodium hydroxide, hydrogen peroxide, glacial acetic acid, hydrochloric acid and sulfuric acid (Farmitalia Carlo Erba, Italy) were used.

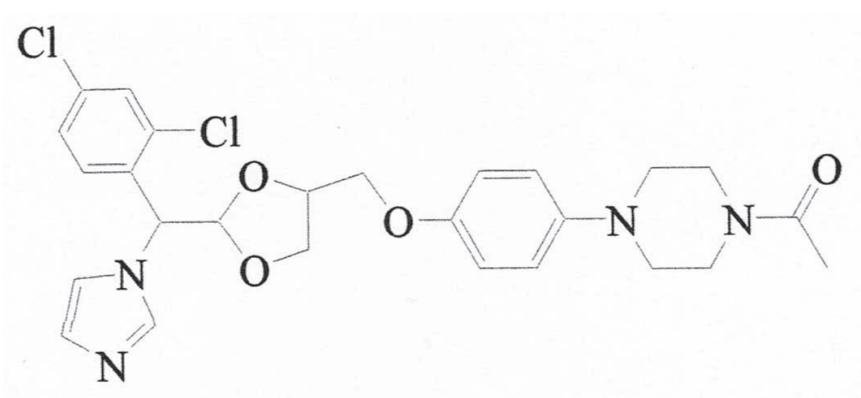

FIGURE 1 - Chemical structure of ketoconazole.

\section{Preparation of mobile phase solutions}

Sodium dodecyl sulphate solution $8 \mathrm{mM}$ was prepared by dissolving $1.15 \mathrm{~g}$ of SDS in $500 \mathrm{~mL}$ with water. Cetylmethylammonium bromide solution $10 \mathrm{mM}$ was prepared by dissolving $1.82 \mathrm{~g}$ of CTAB in $500 \mathrm{~mL}$ with water. Polyoxyethylene lauryl ether solution $10 \mathrm{mM}$ was prepared by dissolving $5.99 \mathrm{~g}$ of Brij ${ }^{\circledR} 35 \mathrm{in} 500 \mathrm{~mL}$ with water. The mobile phase solutions were prepared using deionized water.

\section{Preparation of standard solutions}

The required quantities of the ketoconazole standard was accurately weighed and dissolved in methanol to a final concentration of $1,000 \mathrm{mg} \mathrm{L}^{-1}$. A series of solutions were prepared by further dilution of the stock solutions with mobile phase. The working standards, containing about 1-500 $\mathrm{mg} \mathrm{L}^{-1}$ of ketoconazole were transferred to a $10 \mathrm{~mL}$ volumetric flask, followed by the addition of about $7 \mathrm{~mL}$ mobile phase, sonicated for $5 \mathrm{~min}$ and then made up to $10 \mathrm{~mL}$ with mobile phase.

\section{Preparation of sample solutions}

Three ketoconazole shampoos including: Nora (shampoo A), Kenalyn (shampoo B) and Nizoral (shampoo C) were taken analysis. Each sample contains $2 \%$ of ketoconazole in an aqueous suspension consisting of coconut fatty acid diethanolamide, disodium monolauryl ether sulfosuccinate, hydrochloric acid, imidurea, laurdimonium hydrolyzed animal collagen, macrogol 120 methyl glucose dioleate, perfume bouquet, sodium chloride, sodium hydroxide, sodium lauryl ether sulfate and purified water. Two ketoconazole creams including: Nizoral (cream A) and Ketazon (cream B) were taken for analysis. Each gram of white, odourless cream contains ketoconazole $20 \mathrm{mg}(2 \%)$. Nonmedicinal ingredients are cetyl alcohol, isopropyl myristate, polysorbate, propylene glycol, purified water, sodium bisulfite, 
sorbitan monostearate and stearyl alcohol. All samples were purchased from drug stores in Phitsanulok province, Thailand.

Shampoo and cream samples containing ketoconazole were transferred to a tarred $50 \mathrm{~mL}$ screwcapped centrifuge tube and accurately weighed. A $50-\mathrm{mL}$ of methanol was added (ca 2\%). The tube with loosened cap was shaken for $10 \mathrm{~min}$ and centrifuged at 7,600 rpm for $10 \mathrm{~min}$. The clear supernatant was collected in a stoppered test tube.

\section{Stress degradation of drug substance}

Stress degradation of drug substance studies carried out under acid, base, thermal, photo and oxidative stress conditions followed by Mhaske and Sahasrabudhe (2011).

\section{Acid hydrolysis}

About $250 \mathrm{mg}$ of shampoo and cream samples containing ketoconazole were transferred to a tarred $25 \mathrm{~mL}$ screw-capped centrifuge tube and accurately weighed. A $2 \mathrm{~mL}$ of $1 \mathrm{~N} \mathrm{HCl}$ was added. Sample solution was heated in a boiling water bath at $100{ }^{\circ} \mathrm{C}$, withdrawn at $8 \mathrm{~min}$ and then neutralized with $1 \mathrm{~N} \mathrm{NaOH}$ solution and made up the volume to $25 \mathrm{~mL}$ with methanol. The tube with loosened cap was shaken for $10 \mathrm{~min}$ and centrifuged at 7,600 rpm for $10 \mathrm{~min}$. The clear supernatant was collected in a stoppered test tube. The sample solution was pipette out $4 \mathrm{~mL}$ into $50 \mathrm{~mL}$ volumetric flask and diluted to volume with methanol.

\section{Base hydrolysis}

About $250 \mathrm{mg}$ of shampoo and cream samples containing ketoconazole were transferred to a tarred 25 $\mathrm{mL}$ screw-capped centrifuge tube and accurately weighed. A 2-mL of $1 \mathrm{~N} \mathrm{NaOH}$ was added. Sample solution was heated on boiling water bath at $100{ }^{\circ} \mathrm{C}$, withdrawn at 30 min and then neutralized with $1 \mathrm{~N} \mathrm{HCl}$ solution and make up the volume to $25 \mathrm{~mL}$ with methanol. The tube with loosened cap was shaken for $10 \mathrm{~min}$ and centrifuged at $7,600 \mathrm{rpm}$ for $10 \mathrm{~min}$. The clear supernatant was collected in a stoppered test tube. Four millilitres of the sample solution were pipetted into a $50 \mathrm{~mL}$ volumetric flask and diluted to volume with methanol.

\section{Oxidation}

About $250 \mathrm{mg}$ of shampoo and cream samples containing ketoconazole were transferred to a tarred $25 \mathrm{~mL}$ screw-capped centrifuge tube and accurately weighed. A $2 \mathrm{~mL}$ of $30 \% \mathrm{H}_{2} \mathrm{O}_{2}$ was added. Sample solution was heated in a boiling water bath at $100{ }^{\circ} \mathrm{C}$ withdrawn at $30 \mathrm{~min}$ and then made up to $25 \mathrm{~mL}$ with methanol. The tube with loosened cap was shaken for $10 \mathrm{~min}$ and centrifuged at $7,600 \mathrm{rpm}$ for $10 \mathrm{~min}$. The clear supernatant was collected in a stoppered test tube. Four millilitres of the sample solution were pipetted into a $50 \mathrm{~mL}$ volumetric flask and diluted to volume with methanol.

\section{Thermal}

Test shampoo and cream samples containing ketoconazole were subjected to degradation by exposure to oven at $105^{\circ} \mathrm{C}$ for $24 \mathrm{~h}$. The samples $(250 \mathrm{mg})$ were transferred to a tarred $25 \mathrm{~mL}$ screw-capped centrifuge tube and accurately weighed. Sample solution was made up to $25 \mathrm{~mL}$ with methanol. The tube with loosened cap was shaken for $10 \mathrm{~min}$ and centrifuged at 7,600 rpm for $10 \mathrm{~min}$. The clear supernatant was collected in a stoppered test tube. Four millilitres of the sample solution were pipetted into a $50 \mathrm{~mL}$ volumetric flask and diluted to volume with methanol.

\section{Photolysis}

About $250 \mathrm{mg}$ of shampoo and cream samples containing ketoconazole were kept for photolysis degradation for $24 \mathrm{~h}$ at the wavelength of $254 \mathrm{~nm}$ and dissolved and diluted to $25 \mathrm{~mL}$ with methanol. The tube with loosened cap was shaken for $10 \mathrm{~min}$ and centrifuged at 7,600 rpm for $10 \mathrm{~min}$. The clear supernatant was collected in a stoppered test tube. Four millilitres of the sample solution were pipetted into a $50 \mathrm{~mL}$ volumetric flask and diluted to volume with methanol.

\section{Instrumentation and chromatographic conditions}

An IPLC system consisted of a PerkinElmer ${ }^{\circledR}$ Flexar ${ }^{\circledR}$ HPLC system (PerkinElmer Flexar ${ }^{\circledR}$, Waltham, USA) with a tertiary pump, a fluorescence detector, an auto sampler, an auto injector and Chromera ${ }^{\circledR}$ Chromatography Data Systems (CDS) software. All analyses were performed at room temperature $\left(30^{\circ} \mathrm{C}\right)$. The chromatographic conditions were carried out in the isocratic mode using a mixture of methanol and $8 \mathrm{mM}$ sodium dodecyl sulfate $(\mathrm{pH} 5.5)$ in a ratio of $45: 55 \%$ $\mathrm{v} / \mathrm{v}$ as mobile phase. The flow rate was set at $1.0 \mathrm{~mL}$ $\mathrm{min}^{-1}$. The analytical column was used with $100 \times 4.6 \mathrm{~mm}$ Chromolith ${ }^{\circledR}$ Flash RP-18e analytical column (Merck KGaA Darmstadt, Germany). Each sample and standard aliquots of $10 \mu \mathrm{L}$ were injected by auto sample injector onto the analytical column. Effluent from the analytical column was monitored by fluorescence detection at an excitation wavelength at $260 \mathrm{~nm}$ and an emission wavelength at $375 \mathrm{~nm}$. Quantification was achieved based 
on peak area of ketoconazole. The calibration curve of ketoconazole was constructed by plotting peak areas versus various concentrations of ketoconazole.

\section{System suitability}

System suitability tests were conducted to ensure reproducibility of the equipment. The test was carried out by injecting $10 \mu \mathrm{L}$ of the freshly prepared reference standard solution of ketoconazole $\left(5 \mathrm{mg} \mathrm{L}^{-1}\right)$ five times. System suitability requirements for the assay was an RSD less than $5 \%$, theoretical plate number $(\mathrm{N})$ of at least 2,000 and tailing factor $(\mathrm{T})$ less than 1.5. The proposed method fulfilled these requirements within acceptable limits.

\section{RESULTS AND DISCUSSION}

In order to achieve optimum separation, during the development of the IPLC method for determining ketoconazole, various experimental conditions were investigated.

\section{Section of mobile phase}

During the development of the IPLC method six different compositions of mobile phase including methanol-8 mM sodium dodecyl sulfate, acetonitrile-8 $\mathrm{mM}$ sodium dodecyl sulfate, methanol-10 mM CTAB, acetonitrile-10 mM CTAB, methanol-10 mM Brij ${ }^{\circledR} 35$ and acetonitrile-10 $\mathrm{mM} \mathrm{Brij}{ }^{\circledR} 35$ were tested. In order to achieve determination of ketoconazole with perfect separation and short analysis time, different chromatographic conditions were attempted. The analyte suggested that separated on C18 column with high ratio of aqueous phase. Methanol and acetonitrile were attempted as organic modifier, but the peak shape of ketoconazole was wide, unsymmetrical and tailed after addition of acetonitrile, hence methanol was selected as organic phase. In order to achieve better peak shape, detection sensitivity and higher response, a specified amount of ion-pair reagent was added and SDS was selected as ion-pair reagent to minimize the peak tailing. Aqueous phase of different $\mathrm{pH}$ values were attempted, and finally $\mathrm{pH} 5.5$ was chosen with the best separation condition. Therefore, the mobile phase composition was selected as methanol- $8 \mathrm{mM}$ sodium dodecyl sulfate ( $\mathrm{pH} 5.5$ adjusted with hydrochloric acid) $(45: 55, \mathrm{v} / \mathrm{v})$ at flow rate of $1.0 \mathrm{~mL} \mathrm{~min}^{-1}$. The ketoconazole showed maximum excitation and emission wavelengths at $260 \mathrm{~nm}$ and $375 \mathrm{~nm}$ respectively. The analysis time was about $10 \mathrm{~min}$.

\section{Optimum wavelength}

The optimum absorption wavelength of ketoconazole was also investigated. Ketoconazole standard solution (5 $\mathrm{mg} \mathrm{L}^{-1}$ ) was measured by fluorescence spectrophotometer (JASCO-777, Tokyo, Japan). It was found that the drug gave the maximum excitation and emission wavelengths at $260 \mathrm{~nm}$ and $375 \mathrm{~nm}$ respectively, which was chosen as optimum wavelength.

\section{Summary of the optimum IPLC conditions}

The optimum conditions for IPLC for ketoconazole analysis were summarized in Table I and these conditions were used throughout this work.

\section{Method validation}

The following parameters have been used to validate the developed IPLC method for the estimation of ketoconazole in shampoo and cream samples (ICH, 1996).

TABLE I - Optimized of isocratic IPLC condition for analysis of ketoconazole

\begin{tabular}{lcc}
\hline Operating & & Optimal condition \\
\hline Stationary phase & Chromolith $^{\circledR}$ Flash RP-18e & Chromolith $^{\circledR}$ Flash RP-18e \\
Mobile phase & & \\
$\quad$ Methanol (\%) & $35-50$ & 45 \\
$\quad$ SDS (\%) & $10-60$ & 55 \\
$\quad$ SDS concentration & $1-20 \mathrm{mM}$ & $8 \mathrm{mM}$ \\
$\quad$ pH & $4.5-7.5$ & 5.5 \\
Flow rate & $0.5-2.0 \mathrm{~mL} \mathrm{~min}^{-1}$ & $1.0 \mathrm{~mL} \mathrm{~min}^{-1}$ \\
Wavelength & $200-600 \mathrm{~nm}$ & $\lambda_{\mathrm{ex}} 260 \mathrm{~nm}, \lambda_{\text {em }} 375 \mathrm{~nm}$ \\
Injection volume & $5-50 \mu \mathrm{L}$ & $10 \mu \mathrm{L}$ \\
\hline
\end{tabular}




\section{Sensitivity}

The sensitivity of the assay was determined in terms of limit of detection (LOD), limit of quantitation (LOQ). The detection limit of the method was investigated by applying various concentrations of ketoconazole standard solution on the IPLC system. The limit of detection and limit of quantitation were calculated from the standard deviation (SD) of response and slope of curve (S) using equation;

$$
\begin{aligned}
& \mathrm{LOD}=3.3(\mathrm{SD} / \mathrm{S}) \\
& \mathrm{LOQ}=10(\mathrm{SD} / \mathrm{S})
\end{aligned}
$$

The limit of detection and limit of quantitation were found to be $0.012 \mathrm{mg} \mathrm{L}^{-1}$ and $0.044 \mathrm{mg} \mathrm{L}^{-1}$, respectively.

\section{Linearity}

Linearity of the proposed method was evaluated, by the analysis of working solutions of ketoconazole containing 1-500 $\mathrm{mg} \mathrm{L}^{-1}$ which were injected in triplicate. Ketoconazole were separated on analytical column and determined by using the procedure as mentioned in the experimental section. A linear relationship between peak areas and various concentrations of ketoconazole was established over the range of 1-500 $\mathrm{mg} \mathrm{L}^{-1}$ (Figure 2), with a correlation coefficient of 0.9999 . The results showed excellent correlations within the tested concentrations ranges.

\section{Precision and accuracy}

Precision of the method was established by using solutions of five different concentrations $(1,5,10,15$ and $20 \mathrm{mg} \mathrm{L}^{-1}$ ) of ketoconazole standard solutions. Each solution was determined (triplicate determination) on the same day and relative standard deviation (RSD) was calculated to ascertain intraday precision. The studies were also repeated on three different days to establish interday precision. Results are presented in Table II. The accuracy of the IPLC method was also investigated. Known quantities of ketoconazole were added to previously analyzed samples of ketoconazole and analyzed by

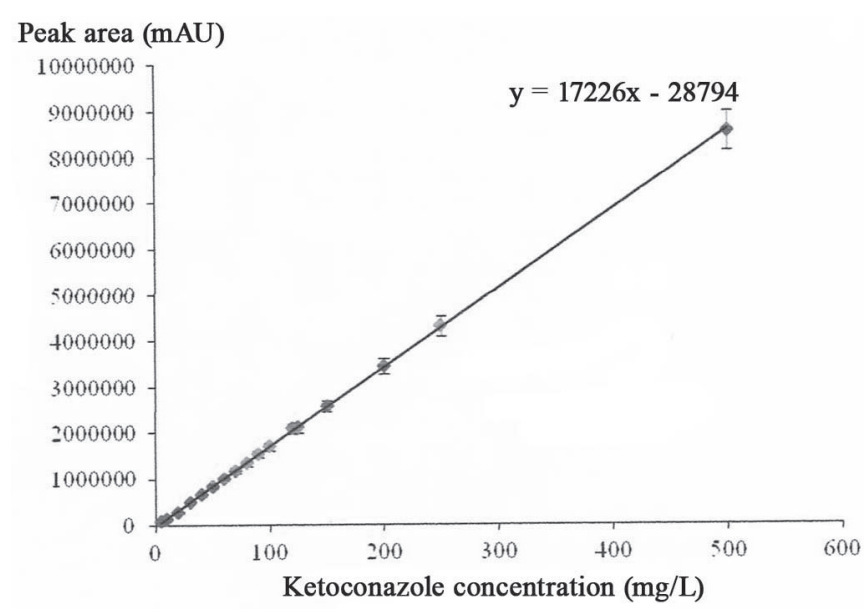

FIGURE 2 - Calibration curve of ketoconazole standard in the concentration range $1-500 \mathrm{mg} \mathrm{L}^{-1}$.

the IPLC method. The average percentage recovery of shampoo A, shampoo B, shampoo C, cream A and cream B were found to be $99.88,97.06,99.58,96.77$ and 97.26 , respectively. The results are presented in Table III.

\section{Robustness}

The robustness study was carried out to evaluate the influence of small, but deliberate variation in the chromatographic conditions. The test was carried out by injecting $10 \mu \mathrm{L}$ of the freshly prepared reference solution of ketoconazole sample ( $2 \%$ ketoconazole cream) three times. The factors chosen for this study which were potential variables in the operating procedures such as temperature of the analytical column $\left( \pm 5^{\circ} \mathrm{C}\right)$, strength of SDS concentration $( \pm 1 \mathrm{mM})$, flow rate $\left( \pm 0.1 \mathrm{~mL} \mathrm{~min}^{-1}\right)$, $\mathrm{pH}$ of mobile phase $( \pm 0.5)$ and strength of organic solvent percentage $( \pm 1 \%)$ were identified. Resolution between ketoconazole and impurities was evaluated in the deliberately altered experimental conditions.

Under all the deliberately altered chromatographic conditions, all peaks were adequately resolved and elution orders remained unchanged, which indicate that the method is robust. Resolution between ketoconazole

TABLE II - Precision study for ketoconazole

\begin{tabular}{ccccc}
\hline \multirow{2}{*}{ Ketoconazole $\left(\mathbf{m g ~ L}^{-1}\right)$} & \multicolumn{2}{c}{ Intra-day precision $(\mathbf{n}=\mathbf{3})$} & \multicolumn{2}{c}{ Inter-day precision $(\mathbf{n}=\mathbf{3})$} \\
\cline { 2 - 5 } & Concentration $\left(\mathbf{m g ~ L}^{-1}\right)$ & \% RSD & Concentration $\left(\mathbf{m g ~ L}^{-\mathbf{1}}\right)$ & \% RSD \\
\hline 1 & 0.99 & 0.02 & 1.01 & 0.02 \\
5 & 4.99 & 0.01 & 4.95 & 0.05 \\
10 & 10.09 & 0.01 & 10.06 & 0.01 \\
15 & 15.02 & 0.02 & 15.02 & 0.02 \\
20 & 19.88 & 0.01 & 19.88 & 0.01 \\
\hline
\end{tabular}


TABLE III - Recovery studies on ketoconazole (Nizoral sample)

\begin{tabular}{|c|c|c|c|}
\hline \multirow{2}{*}{ Ketoconazole in sample } & \multicolumn{2}{|c|}{ Concentration in sample $\left(\mathrm{mg} \mathrm{L}^{-1}\right)$} & \multirow{2}{*}{$\begin{array}{c}\text { \% Recovery }(n=5) \\
(\text { Mean } \pm \text { SD })\end{array}$} \\
\hline & Added & Found & \\
\hline \multirow[t]{5}{*}{ Nizoral } & 1 & 0.99 & $99.43 \pm 2.77$ \\
\hline & 5 & 4.99 & $99.76 \pm 1.34$ \\
\hline & 10 & 10.08 & $100.80 \pm 1.71$ \\
\hline & 15 & 15.01 & $100.06 \pm 0.50$ \\
\hline & 20 & 19.87 & $99.34 \pm 1.40$ \\
\hline average & & & $99.88 \pm 1.54$ \\
\hline
\end{tabular}

and impurity was observed as system suitability in the parameter of the robustness study. Results of this study are provided in Table IV.

TABLE IV- Results of robustness study

\begin{tabular}{lcc}
\hline Parameter / Variation & $\begin{array}{c}\text { Retention time } \\
\text { (min) }\end{array}$ & $\begin{array}{c}\text { Ketoconazole } \\
\text { content (\%) }\end{array}$ \\
\hline As such condition & 5.48 & 2.00 \\
Flow rate $\left(\mathrm{mL} \mathrm{min}{ }^{-1}\right)$ & & \\
$\quad 0.9$ & 6.10 & 1.95 \\
$\quad 1.1$ & 5.11 & 1.86 \\
Column temperature $\left({ }^{\circ} \mathrm{C}\right)$ & & \\
25 & 5.54 & 1.96 \\
$\quad 35$ & 5.40 & 1.76 \\
SDS strength (mM) & & \\
$\quad 7$ & 5.46 & 1.88 \\
9 & 5.54 & 1.74 \\
Organic modifier strength $(\%)$ & & \\
44 & 6.17 & 1.78 \\
46 & 5.35 & 1.65 \\
pH of mobile phase & & \\
5 & 5.52 & 1.93 \\
6 & 5.50 & 1.88 \\
\hline
\end{tabular}

\section{Determination of ketoconazole and stress degradation}

The proposed IPLC method was successfully applied to the determination of ketoconazole in the commercially available shampoo and cream. The contents of ketoconazole in shampoo A, shampoo B, shampoo C and ketoconazole content in cream $\mathrm{A}$ and cream $\mathrm{B}$ were analysed using the procedure as described in experimental section. The results generated by the IPLC method and HPLC reference method were compared with those expected by the label claims (Table V). The results obtained compared favourably with those obtained using the HPLC condition (Smith, McNair, 2003) with an $100 \times 4.6 \mathrm{~mm}$ Chromolith ${ }^{\circledR}$ Flash RP-18e column. Statistical analysis of the results by using $t$-test showed that the calculated $t$-values were less than the table list $t$-value at the $95 \%$ confidential limit $(p=0.069)$. Therefore these two methods are not significantly different in any of the samples. The fluorescence intensity spectrum of ketoconazole, presented a maximum intensity peak at an excitation wavelength at $260 \mathrm{~nm}$ and an emission wavelength at $375 \mathrm{~nm}$, without any interference from excipients. The fluorescence intensity was validated at an emission at $375 \mathrm{~nm}$ with excitation at $260 \mathrm{~nm}$ against a reagent blank treated similarly. To develop an accurate, precise and linear IPLC method for the determination of ketoconazole in shampoo and cream samples as per ICH guidelines. There are compendia methods for quantification of ketoconazole drug substance and formulation official in United States Pharmacopeia (USP). But we found some drawbacks in those methods, which are listed below; almost all of those methods have used organic solvents more than $60 \%$, which is not cost effective for routine analysis in pharmaceutical industries, mobile phase containing organic phase may be detrimental to HPLC analytical column as at that concentration, buffer salts may precipitate and interference caused by different excipients used in newly developed formulation with ketoconazole peak may occur. There are several theories explaining the mechanism of adsorption in ion-pairing chromatography. In the first theory, ions of the ion-pair reagent react with the ionized solute, forming neutral ion-pairs in the mobile phase before its adsorption on the stationary phase. In the second theory, ions of the ion-pair reagent are adsorbed on the hydrophobic stationary phase creating an active ion-exchange surface. The retention of ionic compound can be adjusted by changing the chemical nature and concentration of the ion-pair reagent and by altering the 
proportion of the organic modifier in the mobile phase (Tuzimski, Sherma, 2015). In the case of ketoconazole (basic compound), anionic ion-pairing reagent (SDS) is used to saturate the column at a lower mobile phase concentration. Different compositions of mobile phase were investigated. The ion paring reagent containing 8 $\mathrm{mM}$ sodium dodecyl sulfate, $10 \mathrm{mM} \mathrm{CTAB}$ and $10 \mathrm{mM}$ $\mathrm{Brij}^{\circledR} 35$ were tested. The organic modifier, methanol and acetonitrile were used to separate ketoconazole. The mobile phases consisting of methanol- $8 \mathrm{mM}$ sodium dodecyl sulfate $\mathrm{pH} 5.5(45: 55, \mathrm{v} / \mathrm{v})$ proved to be the best separation time and shape peak; its resolution was good and also demonstrated reproducible well defined peak areas of ketoconazole. The chromatographic conditions were carried out in isocratic mode using a mixture of methanol and $8 \mathrm{mM}$ sodium dodecyl sulfate $(\mathrm{pH} 5.5)$ in a ratio of $45: 55 \%, \mathrm{v} / \mathrm{v}$ as mobile phase. The flow rate was set at $1.0 \mathrm{~mL} \mathrm{~min}^{-1}$. Chromolith ${ }^{\circledR}$ Flash RP-18e column $(100 \times 4.6 \mathrm{~mm})$ was used with fluorescence detection at an excitation wavelength at $260 \mathrm{~nm}$ and an emission wavelength at $375 \mathrm{~nm}$. Under optimum conditions, the developed method resulted in ketoconazole eluting at 5.48 min. The method was validated following ICH guidelines in terms of limit of detection, limit of quantitation, linearity range, precision, accuracy and robustness. The method showed excellent linear response with correlation coefficient $\left(\mathrm{R}^{2}\right)$ values of 0.9999 , which was within the limit of correlation coefficient $\left(\mathrm{R}^{2} \geq 0.995\right)$. Intra and inter-day precision studies of the new method were less than the maximum allowable limit percentage of relative standard deviation $\% \mathrm{RSD} \leq 2.0$. The overall recovery of ketoconazole in the samples was more than $95 \%$ (RSD $<5 \%$ ) which is sufficient for quantification of ketoconazole in formulation samples.

For degradation product, the resulting chromatograms for ketoconazole shampoo and ketoconazole cream obtained under stressed conditions are shown in Figure 3 and Figure 4. The degradation products are well resolved from ketoconazole and do not interfere with its determination. Ketoconazole shampoo and cream samples were found to be quite stable under acid hydrolysis conditions. A slight decomposition was seen on exposure of ketoconazole drug solution to basic and oxidation conditions. On the other hand, the thermal and photolysis conditions underwent rapid degradation. The ketoconazole drug decomposition under thermal and photolysis conditions were found to be $69.05 \%$ and $47.31 \%$ for ketoconazole shampoo, and $87.15 \%$ and $66.83 \%$ for ketoconazole cream, respectively, which indicates that the ketoconazole is more sensitive under photolysis conditions. The ketoconazole decomposition under acidic degradation of shampoo and cream samples were found to be $1.89 \%$ and $1.89 \%$ respectively, indicating that the ketoconazole is resistant towards acidic conditions. The results are shown in Table VI.

\section{CONCLUSION}

In conclusion, the proposed ion-pairing reversed phase HPLC methods were developed to determine ketoconazole in shampoo and cream products. SDS was added into the mobile phase to form ion pairs to enhance retention on reversed-phase HPLC columns. The analytical method utilized isocratic mobile phases in the determination of ketoconazole in formulation. The use of ion-pairing chromatography provides the ability to achieve the desired sensitivity and selectivity in the development of the method. Method development is simple, and a wide variety of separations can be achieved by varying the ionpairing reagent and organic solvent concentration. The detection limit of this method was $0.012 \mathrm{mg} \mathrm{L}^{-1}$. Sample pre-treatment is not necessary. This method is simple,

TABLE V - Comparison of the proposed IPLC method and the HPLC method for the determination of ketoconazole in shampoo and cream formulations

\begin{tabular}{lccc}
\hline \multirow{2}{*}{ Sample } & $\begin{array}{c}\text { Labelled content } \\
(\mathbf{w} / \mathbf{w} \%)\end{array}$ & \multicolumn{2}{c}{$\begin{array}{c}\text { Amounts of ketoconazole found; \% Found } \pm \text { SD } \\
\text { (\% Labelled amount) }\end{array}$} \\
\cline { 3 - 4 } & 2 & IPLC method & HPLC method \\
\hline Shampoo A & 2 & $2.14 \pm 0.25(107.00 \%)$ & $2.32 \pm 0.13(116.00 \%)$ \\
Shampoo B & 2 & $2.18 \pm 0.20(109.00 \%)$ & $2.27 \pm 0.17(113.50 \%)$ \\
Shampoo C & 2 & $2.25 \pm 0.35(112.50 \%)$ & $2.26 \pm 0.25(113.00 \%)$ \\
Cream A & 2 & $2.12 \pm 0.10(106.00 \%)$ & $2.24 \pm 0.27(112.00 \%)$ \\
Cream B & & $2.00 \pm 0.10(100.00 \%)$ & $2.12 \pm 0.27(106.00 \%)$ \\
Paired student's $t$-test & & $P$ value $=0.0997$ & \\
\hline
\end{tabular}



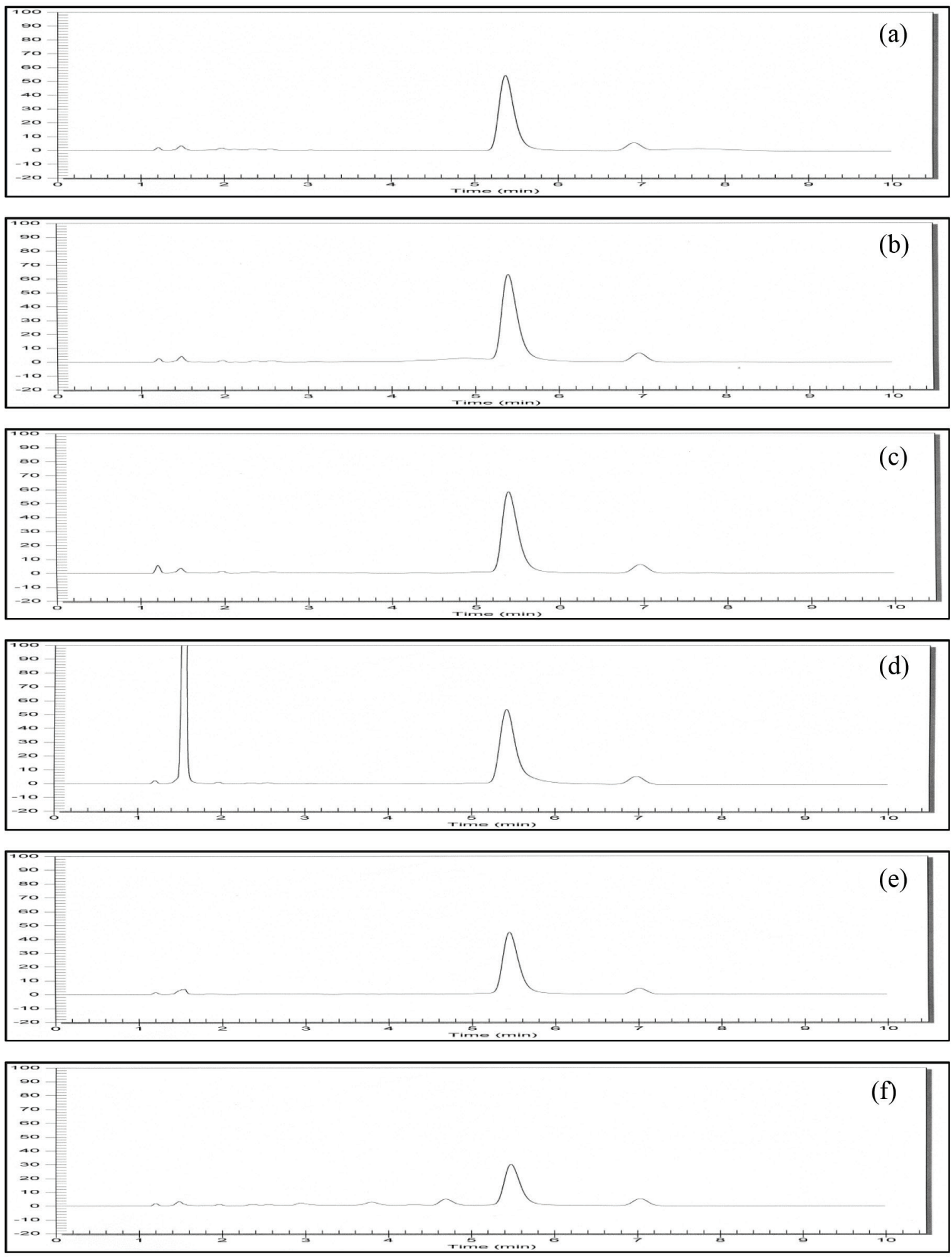

FIGURE 3 - IPLC chromatograms of stressed conditions; (a) ketoconazole shampoo, (b) acid hydrolysis, (c) base hydrolysis, (d) oxidation, (e) thermal and (f) photolysis.

rapid, relatively inexpensive, precise, accurate, sensitive, using minimum number of reagents and chemicals. The speed of analysis and the precision make this method suitable for quality control of ketoconazole in commercial shampoo and cream samples. It is therefore suitable for quality control of ketoconazole in drug industries. 

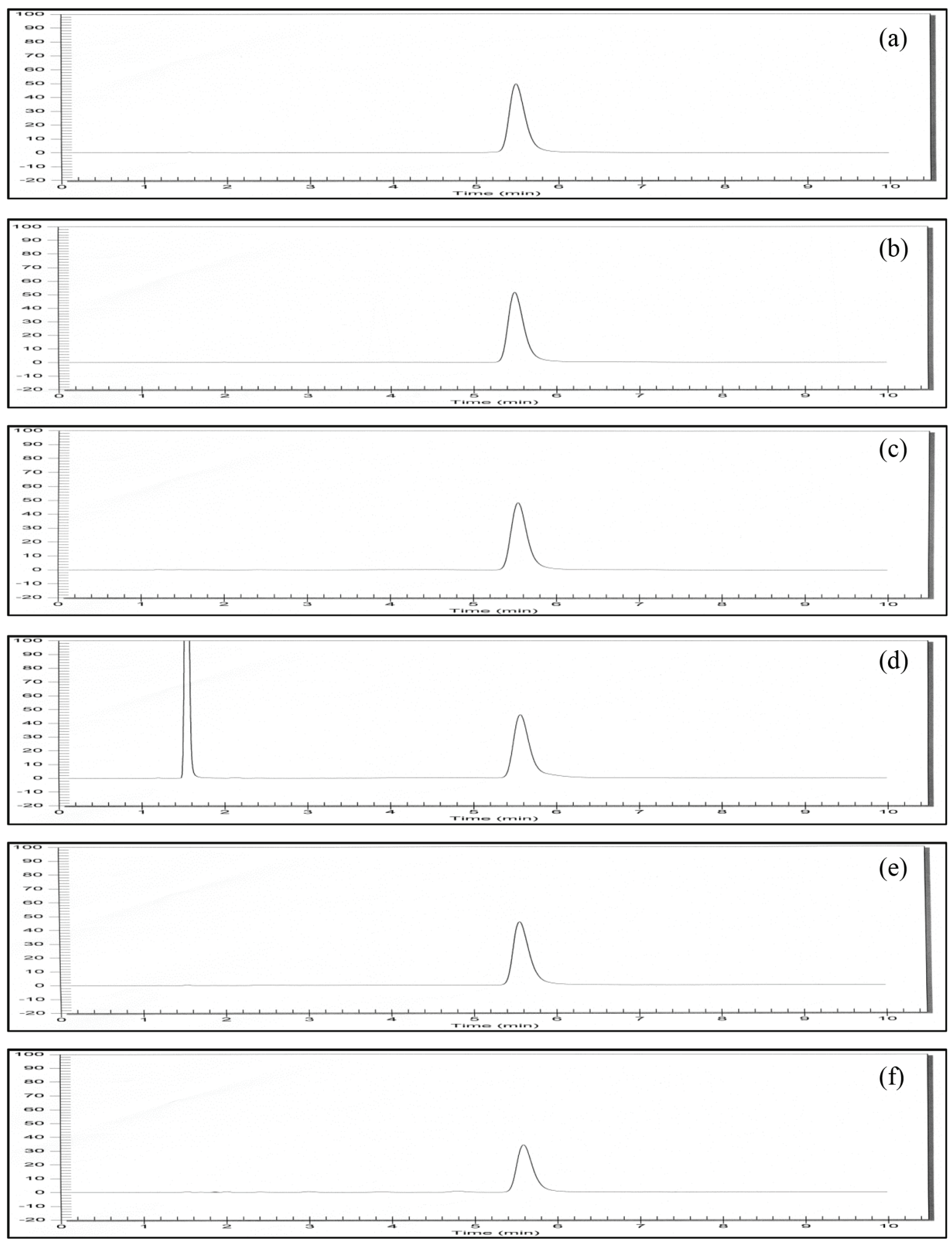

FIGURE 4 - IPLC chromatograms of stressed conditions; (a) ketoconazole cream, (b) acid hydrolysis, (c) base hydrolysis, (d) oxidation, (e) thermal and (f) photolysis.

\section{ACKNOWLEDGEMENTS}

The author would like to express their sincere thank to Program of Chemistry, Faculty of Science and Technology, Pibulsongkram Rajabhat University for their partial support. 
TABLE VI - Results of stress degradation of ketoconazole

\begin{tabular}{lcccccc}
\hline \multirow{2}{*}{ Sample } & \multirow{2}{*}{$\begin{array}{c}\text { Labelled content } \\
(\mathbf{w} / \mathbf{w} \%)\end{array}$} & $\begin{array}{c}\text { Acid } \\
\text { degradation }\end{array}$ & $\begin{array}{c}\text { Base } \\
\text { degradation }\end{array}$ & $\begin{array}{c}\text { Oxidative } \\
\text { degradation }\end{array}$ & $\begin{array}{c}\text { Thermal } \\
\text { degradation }\end{array}$ & UV degradation \\
\hline Shampoo & $2(100 \%)$ & $1.89(94.27 \%)$ & $1.83(91.65 \%)$ & $1.83(91.63 \%)$ & $1.38(69.05 \%)$ & $0.95(47.31 \%)$ \\
Cream & $2(100 \%)$ & $1.89(94.70 \%)$ & $1.88(93.89 \%)$ & $1.86(93.14 \%)$ & $1.74(87.15 \%)$ & $1.34(66.83 \%)$ \\
\hline
\end{tabular}

\section{REFERENCES}

Abdel-Gawad FM. Spectrophotometric determination of some pharmaceutical piperazine derivatives through charge-transfer and ion-pair complexation reactions. J Pharm Biomed Anal. 1997;15(11):1679-85.

Abdel-Moety EM, Khattab FI, Kelani KM, Aboual-Alamein AM. Chromatographic determination of clotrimazole, ketoconazole and fluconazole in pharmaceutical formulations. II Farmaco. 2003;57(11):931-8.

Abou-Attia FM, Issa YM, Abdel-Gawad FM, Abdal-Hami SM. Quantitative determination of some pharmaceutical piperazine derivatives through complexation with iron (III) chloride. II Farmaco 2003;58(8):573-9.

Alizadeh N, Rezakhani Z. Extractive spectrophotometric determination of ketoconazole, clotrimazole and fluconazole by ion-pair complex formation with bromothymol blue and picric acid. J Chil Chem Soc. 2012;57(2):1104-8.

Arranz A, Echevarria C, Moreda JM, Cid A, Francisco JA. Capillary zone electrophoretic separation and determination of imidazolic antifungal drugs. J Chromatogr A. 2000;871(12):399-402.

Arranz P, Arranz A, Moreda JM, Cid A, Arranz JF. Stripping voltammetric and polarographic techniques for the determination of anti-fungal ketoconazole on the mercury electrode. J Pharm Biomed Anal. 2003;33(4):589-96.

Bajad S, Johri RK, Singh K, Singh J, Bedi KL. Simple high-performance liquid chromatography method for the simultaneous determination of ketoconazole and piperine in rat plasma and hepatocyte culture. J Chromatogr A. 2002;949(12):43-47.

Bernal JL, Del Nozal MJ, Toribio L, Montequib MI, Nieto EM. Separation of ketoconazole enantiomers by chiral subcriticalfluid chromatography. J Biochem Biophys Methods. 2000;43(13):241-50.
Bernal JL, Toribio L, Nozal MJ, Nieto EM, Montequi MI. Separation of antifungal chiral drugs by SFC and HPLC: a comparative study. J Biochem Biophys Methods 2002;54(13):245-54.

Bidlingmeyer BA. Separation of ionic compounds by reversephase liquid chromatography: an update of ion-paring techniques. J Chromatogr Sci. 1980;18:525-39.

Bruijn P, Kehrer DFS, Verweij J, Sparreboom A. Liquid chromatographic determination of ketoconazole, a potent inhibitor of CYP3A4-mediated metabolism. J Chromatogr B. 2001;753(2):395-400.

Como JA, Dismukes WE. Oral azole drugs as systemic antifungal therapy. N Engl J Med. 1994;330(4):263-72.

El Ries MA, Abdel Ghany MF, Hussin LA, Fawzy M, El-Anwar AM, Mohamed AM. Voltammetric behavior of ketoconazole and its determination in cosmetic preparation using a $\beta$-cyclodextrin modified glassy carbon electrode. Bull Fac Pharm Cairo Univ. 2013;51(1):49-51.

European Pharmacopoeia. 4th Ed., European Pharmacopoeia Commission; 2002.

Farhadi K, Maleki R. Triiodide ion and alizarin red S as two new reagents for the determination of clotrimazole and ketoconazole. J Pharm Biomed Anal. 2002;30(4):1023-33.

Higuchi T, Michaelis AF. Mechanism and kinetics of ion pair extraction. Rate of extract of dextromethorphanium ion. Anal Chem. 1968;40(13):1925-31.

International Conference on Harmonisation. ICH. Harmonised Tripartite Guideline, Validation of Analytical Procedures: Methodology. Geneva: ICH; 1996. p. 1-8.

Kedor-Hackmann ERM, Nery MMF, Santoro MIRM. Determination of ketoconazole in pharmaceutical preparations by ultraviolet spectrometry and high performance 1 iquid chromatography. Anal Lett. 1994;27(2):363-6. 
Khashaba PY, El-Shabouri SR, Emara KM, Mohamed AM. Analysis of some antifungal drugs by spectrophotometric and spectrofluorimetric methods in different pharmaceutical dosage forms. J Pharm Biomed Anal. 2000;22(2):363-76.

Khalil F, Ramin M. Triiodide ion and alizarin red S as two new reagents for the determination of clotrimazole and ketoconazole. J Pharm Biomed Anal. 2002;30(4):1023-33.

Khashaba PY, El-Shabouri SR, Emara KM, Mohamed AM. Analysis of some antifungal drugs by spectrophotometric and spectrofluorimetric methods in different pharmaceutical dosage forms. J Pharm Biomed Anal. 2000;22(2):363-76.

Leinweber FC, Lubda D, Cabrera K, Tallarek U. Characterization of silica-based monoliths with bimodal pore size distribution. Anal Chem. 2002;74(11):2470-77.

Lyman CA, Walsh TJ. Systemically administered antifungal agents: A review of their clinical pharmacology and therapeutic applications. Drugs. 1992;44(1):9-35.

Mhaske RA, Sahasrabudhe S. Identification of major degradation products of ketoconazole. Sci Pharm. 2011;79(4):817-36.

Naveed S, Jaweed L. UV spectrophotometric assay of Ketoconazole oral formulations. Am J Biol Life Sci. 2014;2(5):108-11.

Nguyen MN, Tallieu L, Plaizier-Vercammen J, Massart DL, Vander Heyden Y. Validation of an HPLC method on short columns to assay ketoconazole and formaldehyde in shampoo. J Pharm Biomed Anal. 2003;32(1):1-19.

Nguyen MN, Van Nederkassel AM, Tallieu L, Kuttatharmmakul S, Hund E, Hu Y, et al. Statistical method comparison: short- and long-column liquid chromatography assays of ketoconazole and formaldehyde in shampoo. Anal Chim Acta. 2004;516(12):87-106.

Rader BR. Application of ion-pairing to separation of selected sulfonamides by partition chromatography. J Pharm Sci. $1973 ; 62(7): 1148-50$.

Rane SS, Padmaja P. Spectrophotometric method for the determination of ketoconazole based on amplification reactions. J Pharm Anal. 2012;2(1):43-7.

Sadeghi S, Shamsipur M. A new extractive-spectrophotometric method for the determination of ketoconazole from pharmaceutical preparations. Anal Lett. 1998;31(15):2691-705.
Smith JH, Mcnair HM. Fast HPLC with a silica-based monolithic ODS column. J Chromatogr Sci. 2003;41(4):209-14.

Su SC, Hartkopf AV, Karger BL. High-performance ion-pair partition chromatography of sulfa drug study and optimization of chemical parameters. J Chromatogr A. 1976;119:523-38.

Suwanna S, Boonsom L, Saisunee L. High-performance thin-layer chromatographic determination of ketoconazole in pharmaceutical formulations. J Cosmet Sci. 2010;61(5):367-76.

Tanaka N, Kobayashi H, Ishizuka N, Minakuchi H, Nakanishi K, Hosoya K, et al. Monolithic silica columns for high-efficiency chromatographic separations. J Chromatogr A. 2002;965(12):35-49.

The United States Pharmacopoeia. 25th Ed. Rockwille: United States Pharmacopeial Convention; 2002.

Tuzimski, Sherma J. High performance liquid chromatography in pesticide residue analysis. CRC Press; 2015. 582 p.

Vander Heyden Y, Nguyen minh, Nguyet A, Detaevernier MR, Massart DL, Plaizier-Vercammen J. Simultaneous determination of ketoconazole and formaldehyde in a shampoo: liquid chromatography method development and validation. J Chromatogr A. 2002;958(1-2):191-201.

Velikinac I, Cudina O, Jankovi I, Agbaba D, Vladimirov S. Comparison of capillary zone electrophoresis and high performance liquid chromatography method for quantitative determination of ketoconazole in drug formulations. II Farmaco. 2004;59(5):419-24.

Vertzoni MV, Reppas C, Archontaki HA. Optimization and validation of a high-performance liquid chromatographic method with UV detection for the determination of ketoconazole in canine plasma. J Chromatogr B. 2006;839(1-2):62-7.

Wang K, Wu Y, Chi Z, Shu C, Li L, Wei J, et al. A highly sensitive LC-MS/MS method for determination of ketoconazole in human plasma: Application to a clinical study of the exposure to ketoconazole in patients after topical administration. J Pharm Biomed Anal. 2016;128:504-9.

Received for publication on $05^{\text {th }}$ October 2016 Accepted for publication on $14^{\text {th }}$ March 2018 